\title{
LIVER-SPECIFIC STEM CELLS AND HEPATOCELLULAR CARCINOMA: AN IN VITRO COMPARISON BETWEEN STEM CELLS ISOLATED FROM MALIGNANT AND NON- MALIGNANT HUMAN LIVER TISSUE.
}

\author{
Tamer A. Al-Shafiea ${ }^{(1-8)}$, Haitham A. Badr ${ }^{(2)}$, Dina M.M. AlSadek ${ }^{(3)}$, Sabry M. El-Bahrd ${ }^{(4,5)}$, Hafiz \\ Ahmed $^{(8)}$, Alaa Ismailg, ${ }^{(7)}$ Motawa E. El-Houseini $^{(8)}$, Mennatallah A. Alia ${ }^{(1)}$ \\ (1) Departments of Pharmacology and Toxicology, Faculty of Pharmacy and Drug Manufacturing, Pharos University, Egypt \\ (2) Department of Biochemistry, Faculty of Agriculture, Zagazig University, Egypt \\ (3) Department of Histology and Cytology, Faculty of Veterinary Medicine, Zagazig University, Egypt \\ ${ }^{(4)}$ Department of Physiology, Biochemistry, and Pharmacology, King Faisal University, Saudi Arabia \\ ${ }^{(5)}$ Department of Biochemistry, Faculty of Veterinary Medicine, Alexandria University, Egypt \\ (6) GylcoMantra, Inc., Baltimore, USA \\ ${ }^{(7)}$ Department of Surgery, Faculty of Medicine, Ain Shams University, Egypt \\ ${ }^{(8)}$ Cancer Biology Department, National Cancer Institute, Cairo University, Egypt
}

\section{ABSTRACT:}

Background: Hepatocellular carcinoma (HCC) is the most common primary tumor of the liver. Traditional therapies might not be sufficient to eradicate total tumor because they target mainly the differentiated cells. Liver transplantation is a treatment method but donors are not easily available. Liver stem cell-targeted therapy is considered to increase the efficiency and safety of the treatment. Studies suggest that liver-specific stem cells might be involved in liver regeneration and liver carcinogenesis, but more researches are needed to confirm these facts. We designed this work to characterize and compare between in vitro cultured liver stem cells isolated from malignant and non-malignant tumor tissue over a period of a month. \% CD133 expression was determined by flow cytometry. Our results showed a significant increase in CD133 expression in stem cells isolated from malignant liver tissues compared with those isolated from non-malignant liver tissues $(\mathrm{p}=0.0004)$. Interestingly, prolonged cultured stem cells isolated from malignant liver tissue were found to proliferate while those isolated from non-malignant liver were found to be differentiated. However, further studies are needed to elucidate the role of liver-specific stem cells in liver cancer development and recurrence

Keywords: Hepatocellular carcinoma, liver specific stem cells, cancer stem cell (CSC), in vitro culture.

\section{INTRODUCTION}

Hepatocellular carcinoma (HCC) is an aggressive tumor with mean survival 6-20 months. Liver transplantation is a reasonable treatment. Unfortunately, the organ donors for liver transplantation are not readily available and so therapeutic treatments become the most practical alternative strategies. $\left({ }^{1,2}\right)$
In normal liver, liver-specific stem cells are small cells reside in the canals of Hering $(\mathrm{CoH})$ with an oval nucleus and small cytoplasm. They can express surface proteins in common with mature hepatocytes (albumin, CK-8), immature foetal hepatoblasts ( $\alpha$-fetoprotein), and haematopoietic stem cells (CD133, cKit). (4)

The liver is one of the few organs that are known to be capable of rapid regeneration. This process usually takes place in response to liver injury resulting from surgical resection or exposure to destructive agents. (5) Liver injury can also facilitate the transformation process including long-lasting inflammation and regeneration, chronic viral infection, alcoholic, or non-alcoholic fatty liver disease. ${ }^{(6)}$

Studies suggest that, during these conditions, stem cells expansion, accumulation of genetic and epigenetic changes, and alteration of the microenvironment occur continuously. This might result in the transformation of liver-specific stem cells to cancer stem cells (CSCs) followed by the initiation and promotion of liver cancer. ${ }^{(7)}$ 
Other studies suggest a possibility that liver-specific stem cells have an important role in modulating the regeneration process following liver injury; however, no sufficient evidence supports these hypotheses 8 .

\section{AIM OF THE WORK:}

The objective of this work is to study the biological behavior of stem cells isolated from liver tissue in vitro and to perform a comparative analysis of cultured stem cells isolated from malignant liver tissue and those isolated from non-malignant liver tissue.

\section{MATERIALS AND METHODS:}

\section{Liver tissue specimens:}

Under the approval of Institutional Review Board (IRB), liver tissues were collected from patients with hepatocellular carcinoma $(\mathrm{N}=20)$ after partial hepatectomy.

\section{Histopathology:}

To differentiate malignant and non-malignant liver tissue histopathological examination was done for freshly excised liver tissue.

Fixation of excised liver tissue was done in $10 \%$ phosphate - buffered neutral p- formaldehyde (Sigma Chemical Co.) for 6-8 hours, and then transferred to $70 \%$ ethanol. Fixed tissues were embedded in paraffin sections $(\sim 5 \mu \mathrm{m})$ and stained with $\mathrm{H} \& \mathrm{E}$ for examination.

\section{Cell disaggregation and fractionation:}

Disaggregation and fractionation of liver cells were performed according to Grozdanov et al.8 and Laurson et al. 9 with minor modifications. Briefly, each malignant and non-malignant liver tissue was washed with hypotonic saline and equal volume of DMEM with 5\% antibiotic - antimycotic solution.

Then, each tissue was minced and digested with collagenase - III to obtain a cell suspension of each malignant and non-malignant liver tissue separately. Each supernatant was passed through $100 \mu \mathrm{m}$ mesh and centrifuged at $1,000 \mathrm{xg}$ for $10 \mathrm{~min}$.

Liver cell suspensions were centrifuged at 50xg for $1 \mathrm{~min}$ 3 times, and then final supernatant was layered on Ficoll Paque (Biowest, France) and centrifuged for $20 \mathrm{~min}$ at $800 \mathrm{xg}$ to separate liver stem cells in the middle layer.

\section{Cell culture:}

Liver stem cells were cultured in T-25 tissue culture flasks containing DMEM medium with glutamine and non-essential amino acids, supplemented with $20 \mathrm{ng} / \mathrm{ml}$ basic fibroblast growth factor (b-FGF), epidermal growth factor (EGF) (Biowest Inc.-France).

Cultures were maintained at $37^{\circ} \mathrm{C}$ in a humidified incubator in a mixture of $95 \%$ air and $5 \% \mathrm{CO} 2$.

\section{Determination of liver stem cell marker (\% CD133) by} flow cytometry:

Human CD133 monoclonal antibodies conjugated to fluorescein isothiocyanate (FITC) (Miltenyi Biotec Inc., Germany) were used for characterization of liver stem cells by flow cytometry (BD FACSCaliburTM laser flow cytometer, BD Biosciences).

\section{RESULTS}

Twenty excised liver tissue specimens were taken after partial hepatectomy from patients with hepatocellular carcinoma under the approval of Institutional Review Board (IRB) (Fig. 1A). Age of patients ranged from 5065 years $(57.5 \pm 2.5$ years old $)$. Number of total patients was 20 - of which 13 were male and 7 were female.

Malignant and non-malignant portion in each excised liver tissue was separated from each other and processed separately (Fig. 1B \& 1C).

To ensure malignant and non-malignant pieces before cell disaggregation, histopathological examination was performed for each piece (Fig. 2A \& 2B).

Each liver malignant and non-malignant liver piece was undergone cell disaggregation and cell culture. Cell suspension containing all liver cell types for each pair was cultured and examined under microscope (OLYMPUS inverted microscope, Life Science Company).

Hepatocytes were the most prominent cells in all liver cell types (70-80\%), with polygonal shape and large size (Fig. 3B).

Liver stem cells were separated from liver cell suspension and cultured. They show spheroidal shape and smaller size (Fig. 3A).

Flowcytometric characterization using \%CD133 was performed for stem cells isolated from malignant and nonmalignant liver cells. The percentage of CD133 expression was significantly higher in liver cells isolated from malignant tissues in comparison with those isolated from non-malignant tissues, $\mathrm{p}$-value $=0.0004$ (Table 1 ) (Fig. 4 \& 5).

Liver stem cells isolated from malignant and nonmalignant liver tissues were cultured and microscopically examined over time (OLYMPUS inverted microscope, Life Science Company).

Stem cells isolated from non-malignant liver tissues showed signs of differentiation which involved changes in morphologies from rounded spherical shape at day 19 (Fig. 6A) into spindle shape at day 23 (Fig. 6B) and epithelial-like shape at day 31 (Fig. 6C).

On the other hand, stem cells isolated from malignant liver tissues increased in number from day 9 (Fig. 7A), day 15 (Fig. 7B) and day 29 (Fig. 7C). 


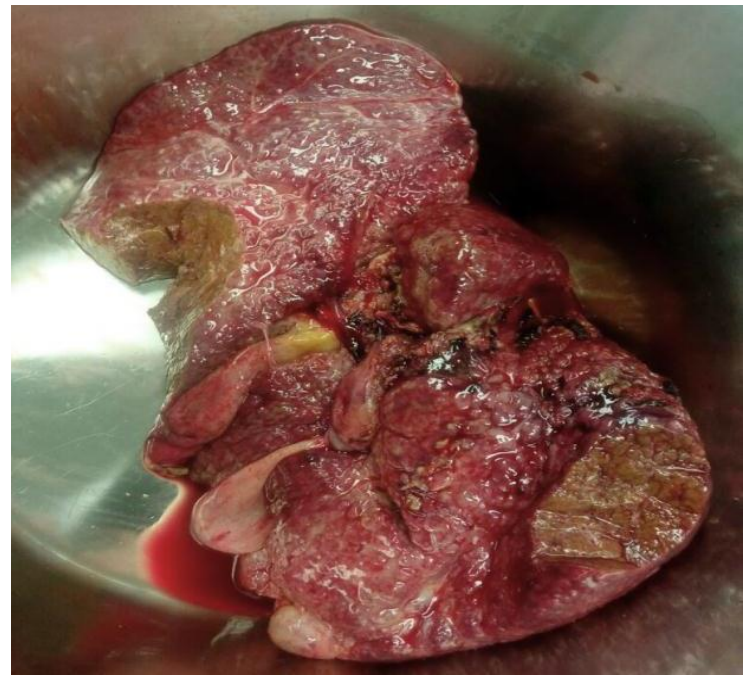

(A)

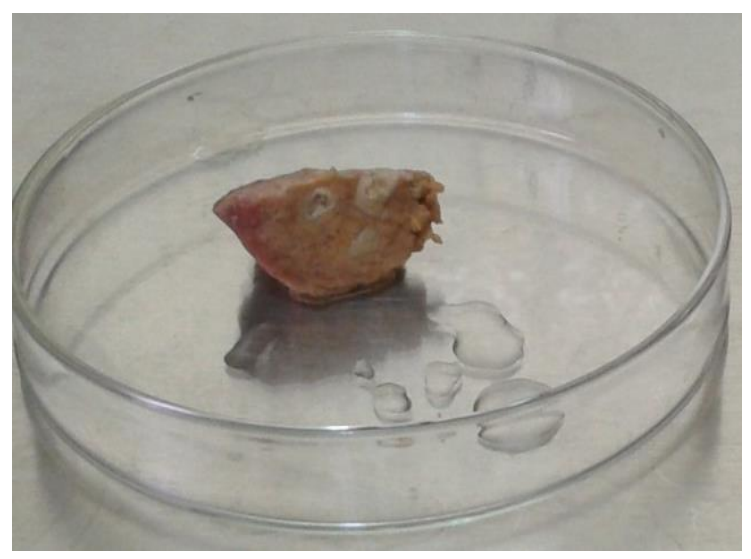

(B)

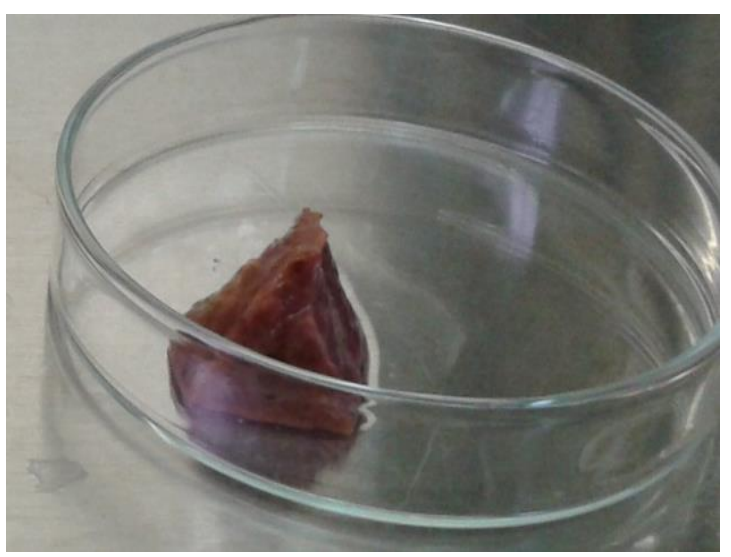

(C)

Fig (1): Excised liver tissue after partial therapeutic hepatectomy (A) contains: non-malignant piece (B) and malignant piece (C).

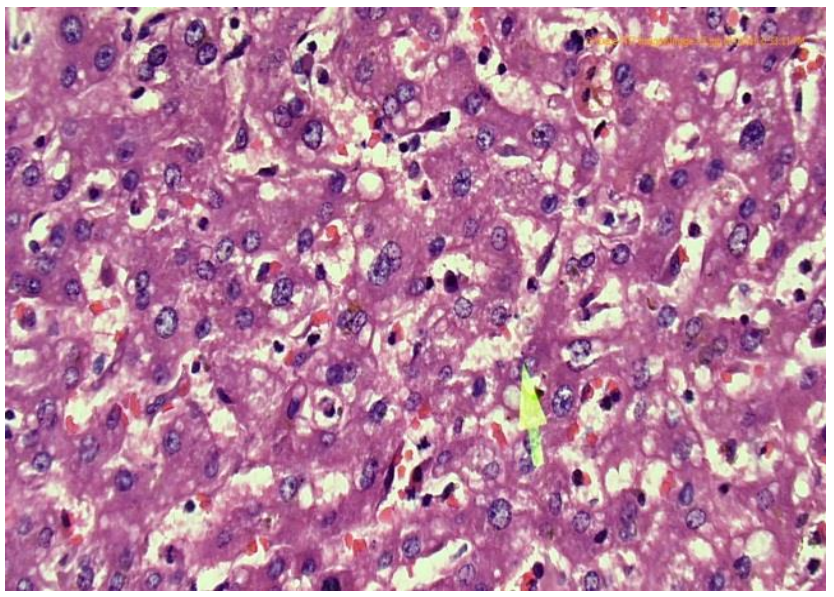

(A)

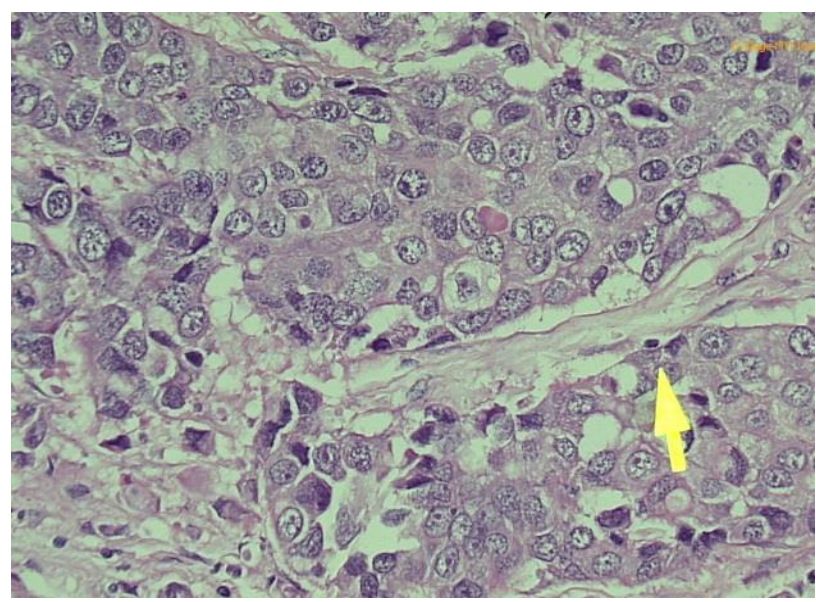

(B)

Fig (2): Histopathological examination (H \& E stain) for non-malignant liver tissue (A) and malignant liver tissue (B).

LIVER-SPECIFIC STEM CELLS AND HEPATOCELLULAR CARCINOMA: AN IN VITRO COMPARISON BETWEEN STEM CELLS ISOLATED FROM MALIGNANT AND NON- MALIGNANT HUMAN LIVER TISSUE. 


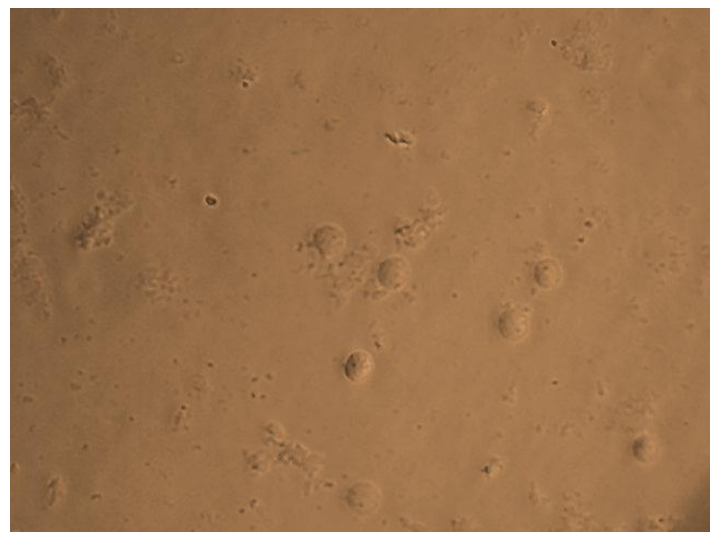

(A)

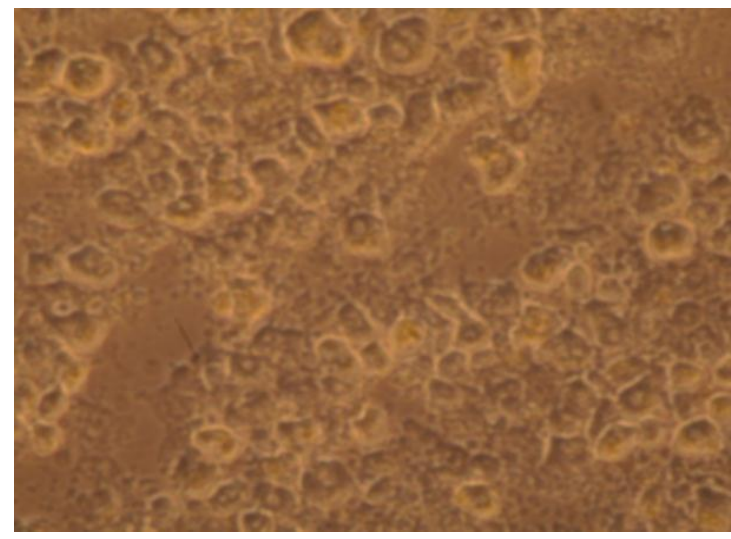

(B)

Fig (3): (A) Liver tissue stem cells isolated from malignant and non-malignant liver pieces and cultured at day 1, magnification 10x showing spheroidal in shape. (B) Hepatocytes (liver parenchymal cells) isolated from malignant and non-malignant liver pieces and cultured at day 1, magnification 20x showing polygonal shape

Table (1):Mean percentage of CD133 expression in stem cells isolated from malignant and non-malignant liver tissues.

\begin{tabular}{|c|c|c|c|c|}
\hline Marker \% & $\begin{array}{l}\text { Stem cells isolated from malignant } \\
\text { liver tissue } \\
(n=20)\end{array}$ & $\begin{array}{l}\text { Stem cells isolated from non- } \\
\text { malignant liver tissue } \\
(n=20)\end{array}$ & $t$-test & p-value \\
\hline CD133 & $10.1 \% \pm 2.42$ & $4.8 \% \pm 1.83$ & 5.406 & 0.0004 \\
\hline
\end{tabular}

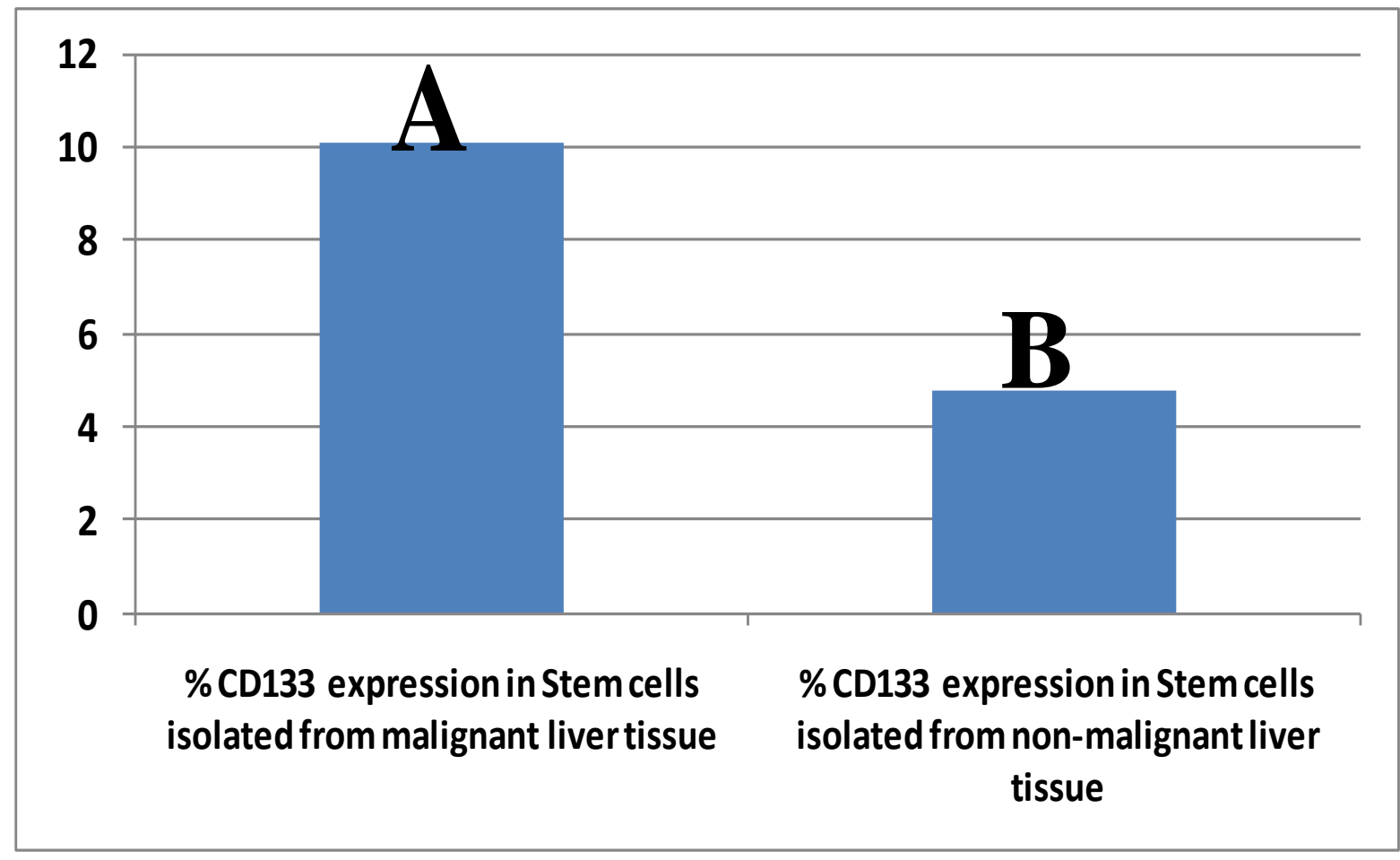

Fig (4): Comparison between \% CD133 expression in stem cells isolated from malignant liver tissue (10.1\% \pm 2.42$)$, Column (A) and non-malignant liver tissue $(4.8 \% \pm 1.83)$, Column $(\mathbf{B})$. T-test $=5.40$ and $p<0.001$ 

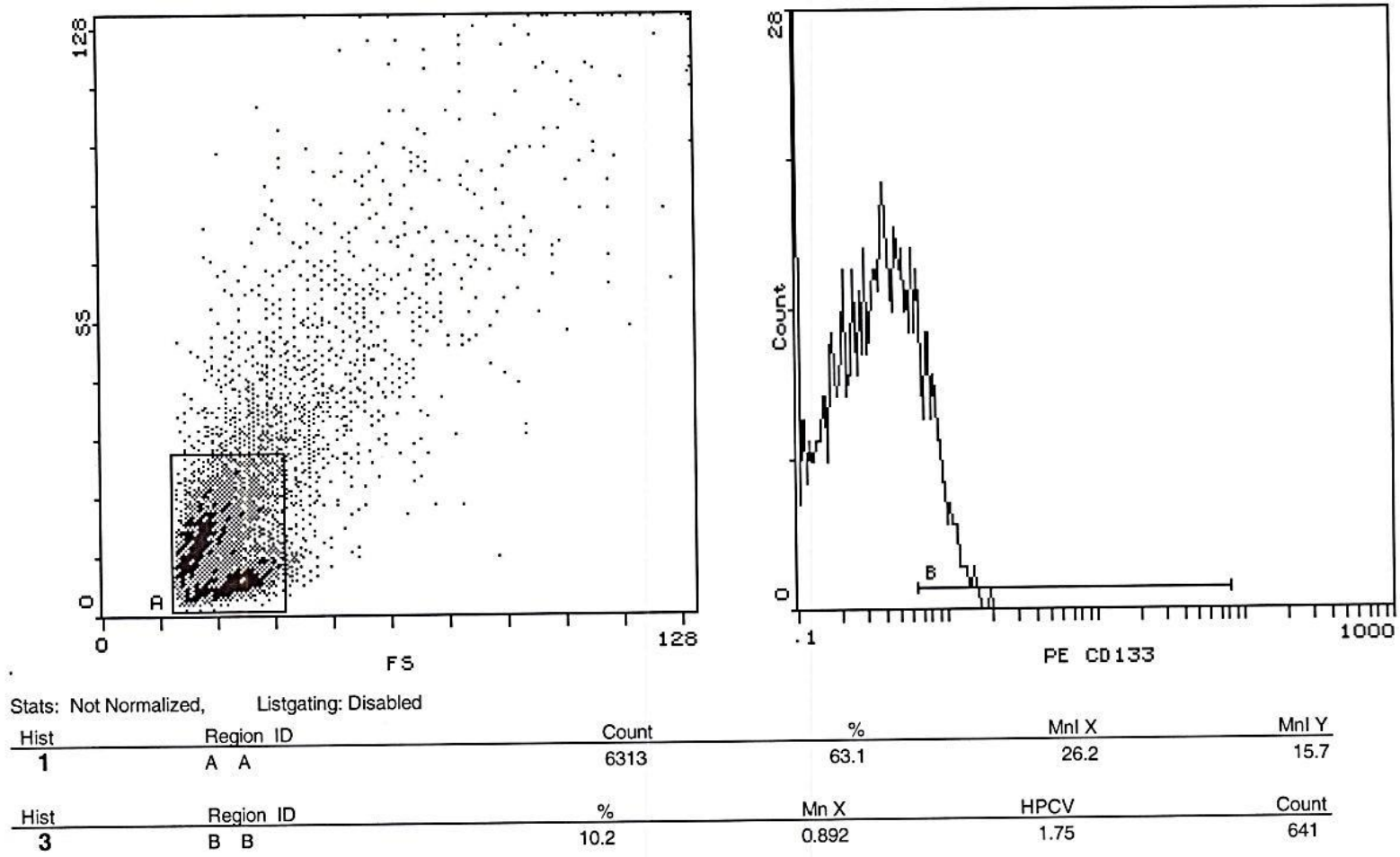

(A)
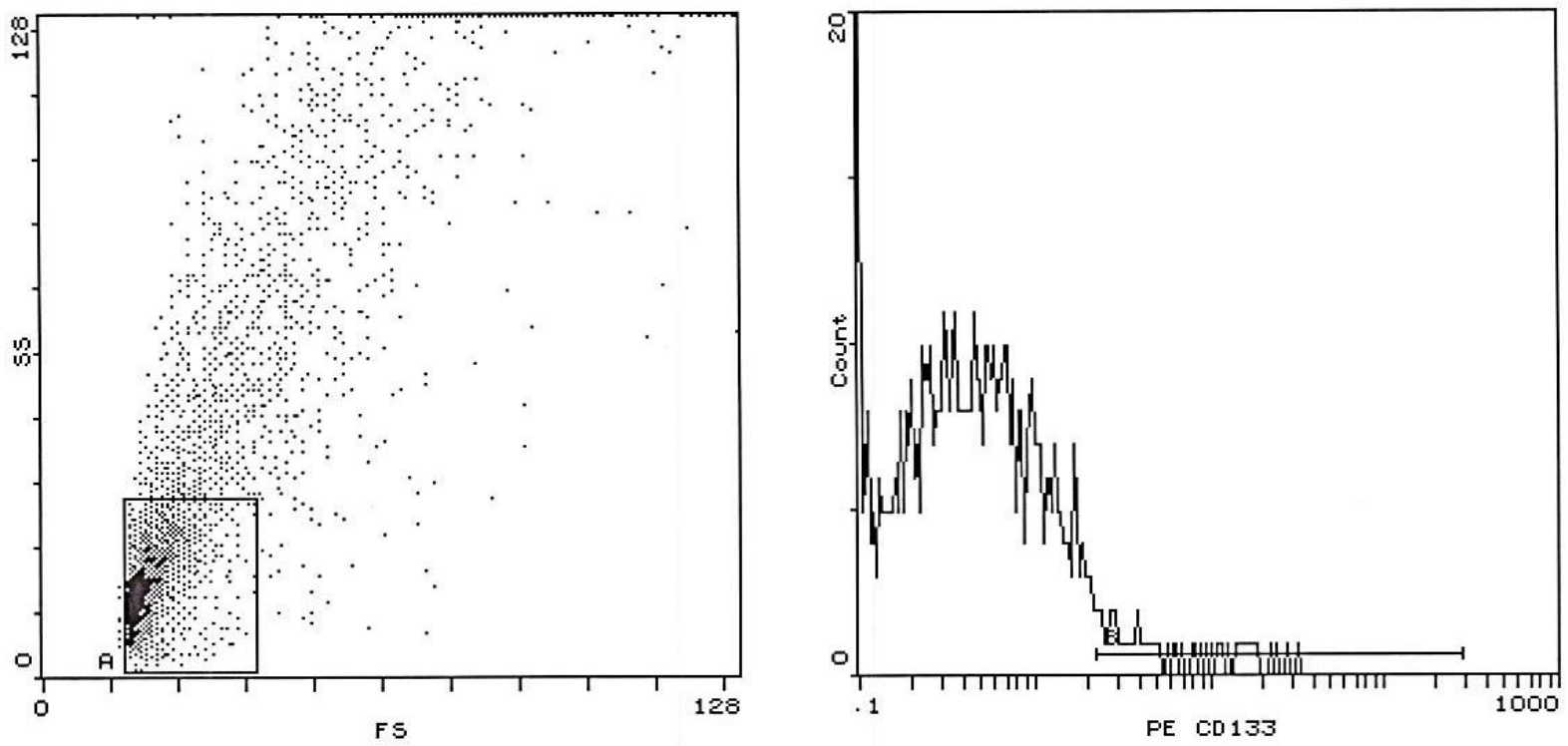

Stats: Not Normalized, Listgating: Disabled

\begin{tabular}{|c|c|c|c|c|c|}
\hline Hist & Region ID & Count & $\%$ & Mnl X & Mnl Y \\
\hline 1 & A A & 4896 & 49.0 & 20.6 & 18.3 \\
\hline Hist & Region ID & $\%$ & $\mathrm{MnX}$ & $\mathrm{HPCV}$ & Count \\
\hline
\end{tabular}

\section{(B)}

Fig (5): Representative flow cytometric characterization of stem cells isolated from liver tissue using \%CD133 showing dotblott and histogram. (A) \%CD133 in liver stem cells isolated from malignant liver tissue is 10.2\%. (B) \% CD133 in liver stem cells isolated from malignant liver tissue is $4.15 \%$. 


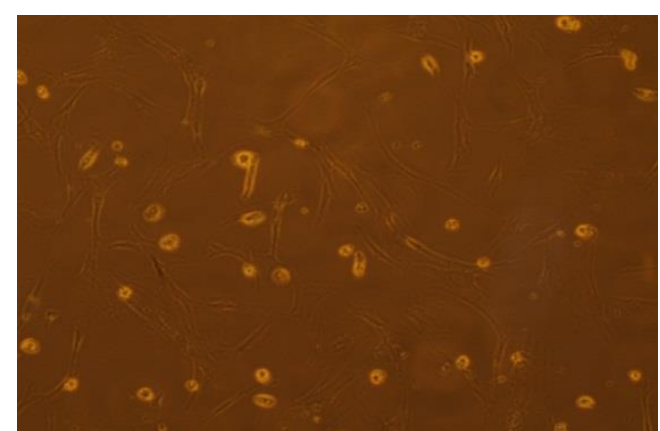

(C)

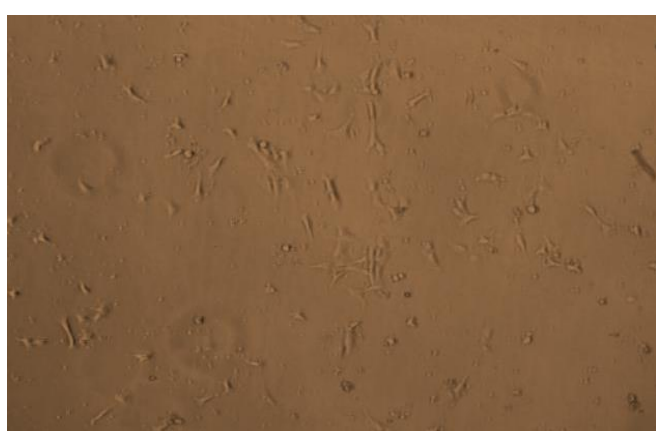

(B)

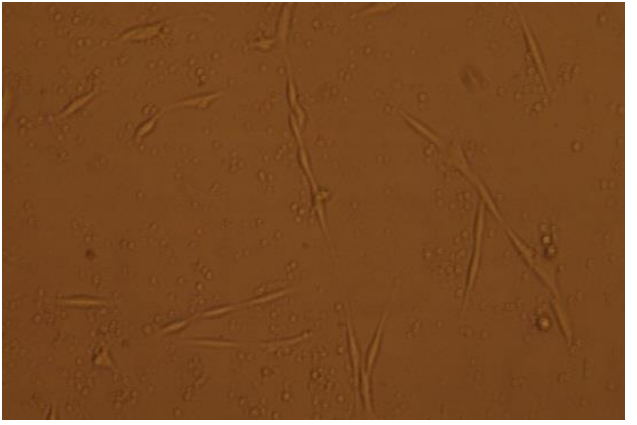

(B)

Fig (6): Differentiation of stem cells isolated from non-malignant liver tissue in culture. (A) day 19, (B) day 23 and (C) day 31 , magnification 10x. Stem cells show change in morphology from spherical shape into spindle and epithelial shape.

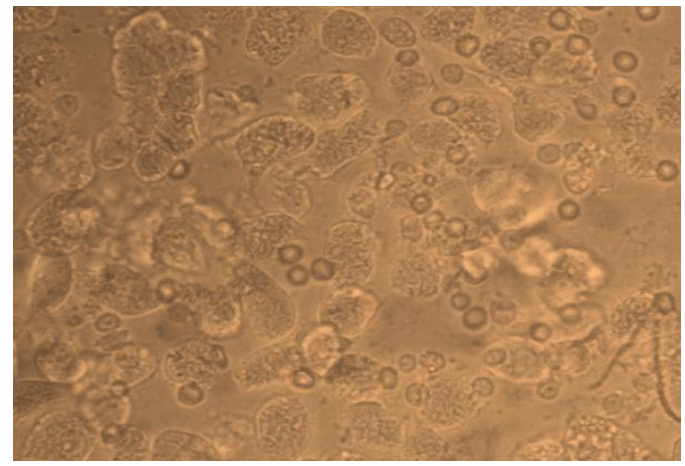

(A)

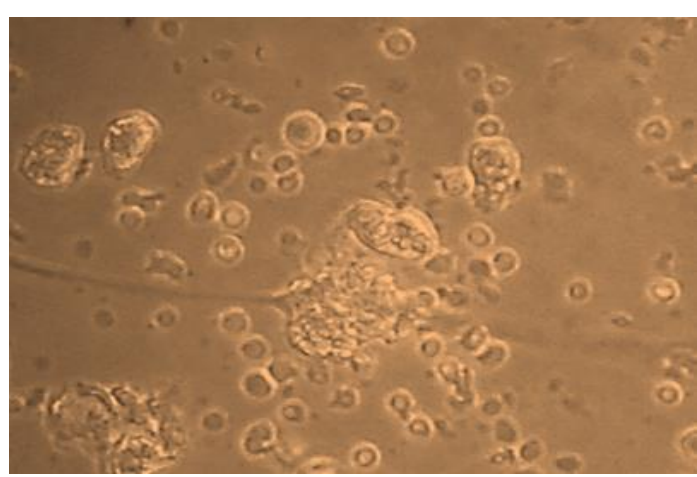

(B)

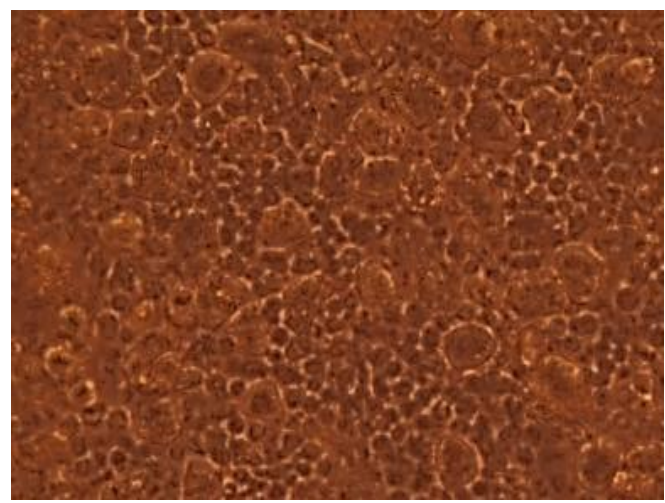

(C)

Fig (7): Proliferation of stem cells isolated from malignant liver tissue in culture. (A) day 9, (B) day 15 and (C) day 29 , magnification 10x. Stem cells show increase in number but no differentiation was monitored over this time period. 


\section{DISCUSSION}

The development of regenerative medicine and liver cellbased therapy has drawn attention to the liver-specific stem cells as a vehicle to restore normal structure and function after tissue injury. Hence, it becomes important to study the biology of liver-specific stem cells in vitro to determine their role in liver carcinogenesis. ${ }^{(10)}$

In this work, we compared in vitro cultured stem cells isolated from malignant liver tissue with those isolated from non-malignant liver tissue.

Liver-specific stem cells are a group of parenchymal cells that are capable of in vivo differentiation into hepatocytes for the maintenance of liver cell population

Liver parenchyma comprises a heterogeneous population of cells, namely, hepatocytes, bile duct epithelia and nonparenchymal cells (NPCs) including Kupffer, endothelial, mesothelial and inflammatory cell ${ }^{(12)}$

Our microscopic images for liver stem cells showed spherical shape and small diameter in comparison with the main liver cells; hepatocytes, which are polygonal and larger. This descriptive morphology of liver stem cells and hepatocytes is consistent with many other investigators. ${ }^{(13,14,15)}$

The analysis of liver stem cells reveals the presences of characteristic cell surface proteins associated either hematopoietic (e.g. CD34 and CD45), endothelial (e.g. CD31) or mesenchymal (e.g. CD44 and CD90). ${ }^{(16)}$

CD133 is a characteristic marker of hematopoietic stem cells, neuronal stem cells, and liver stem cells. It plays a role in the maintenance of CSC properties by regulating interleukin (IL)-8, CXCL1, and MAPK signaling. ${ }^{(17)}$

CD133 expression increases in liver cancer stem cells. It has a clinical significance; the patients with high CD133 expression have poor overall survival and higher recurrence rates compared with patients with low CD133 expression $(18,19)$

We determined and compared the percent of CD133 expression. Our data showed CD133 expression in both malignant and non-malignant liver tissues with a significant increase in CD133 in malignant compared to non-malignant liver tissues $(\mathrm{p}<0.001)$ which confirm the importance of CD133 as a prognostic marker in both liver cirrhosis and hepatocellular carcinoma.

Normal stem cells comprise a small proportion have an important role in organ maintenance by proliferation and differentiation particularly after injury. Cancer stem cells are believed to lose regulation controlling self-renewal ${ }^{20}$ and profiling the glycosylation status of cancer cells can be used to successfully reduce the risk of developing cancers. ${ }^{(21)}$

In our work, during prolonged culture, stem cells isolated from malignant liver tissue were observed to proliferate while those isolated from non-malignant liver tissue were destined to differentiation.
Indeed, proliferation of liver-specific stem cells during carcinogenesis contributes to increased organ size and tumor formation with impaired liver function. On the other hand, differentiation of liver-specific stem cells in non-malignant conditions contributes to restore liver structure and function. Further studies are needed to address whether obligation of liver stem cell to differentiate in precancerous states can prevent the development of liver cancer.

\section{CONCLUSION}

Liver-specific stem cells isolated from malignant liver tissue tend to proliferate while liver tissue-specific stem cells isolated from non-malignant liver tissue tend to differentiate. This finding suggests that liver-specific stem cells have a major role in liver cancer development and tumor recurrence.

\section{REFERENCES}

1. Cantz T, Manns MP, Ott M. Stem cells in liver regeneration and therapy. Cell Tissue Res. 2008; 331:271-82.

2. Byam J, Renz J, Millis JM. Liver transplantation for hepatocellular carcinoma. Hepatobiliary Surg Nutr 2013; 2:22-30.

3. Gaudio E, Carpino G, Cardinale V, Franchitto A, Onori $P$, Alvaro D. New insights into liver stem cells. Dig Liver Dis 2009; 41:455-62.

4. Zhang L, Theise N, Chua M, Reid LM. The stem cell niche of human livers: symmetry between development and regeneration. Hepatology 2008; 48:1598-607.

5. Darwiche H, Petersen BE. Biology of the adult hepatic progenitor cell: "ghosts in the machine". Prog Mol Biol Transl Sci. 2010; 97:229-49.

6. Yamashita T, Wang XW. Cancer stem cells in the development of liver cancer. J Clin Invest. 2013; 123:1911-8

7. Cheng Z, Li X, Ding J. Characteristics of liver cancer stem cells and clinical correlations. Cancer Lett. 2016; 379:230-8.

8. Grozdanov PN, Yovchev MI, Dabeva MD. The oncofetal protein glypican-3 is a novel marker of hepatic progenitor/oval cells. Lab Invest. 2006; 86:1272-84.

9. Laurson J, Selden C, Clements M, Mavri-Damelin D, Coward S, Lowdell M, Hodgson HJF. Putative Human Liver Progenitor Cells in Explanted Liver. Cells Tissues Organs 2007; 186:180-91.

10. Garate Z, Davis BR, Quintana-Bustamante O, Segovia JC. New frontier in regenerative medicine: Site-specific gene correction in patient-specific induced pluripotent stem cells. Hum Gene Ther. 2013; 24:571583.

11. Tosh D and Strain A. Liver stem cells-prospects for clinical use. J Hepatol 2005; 42:S75-84.

12. Wee A. Fine needle aspiration biopsy of the liver: Algorithmic approach and current issues in the diagnosis of hepatocellular carcinoma. CytoJournal 2005; 2:7-23.

13. Turner R, Lozoya O, Wang Y, Cardinale V, Gaudio E, Alpini G, Mendel G, Wauthier E, Barbier C, Alvaro D. Human hepatic stem cell and maturational liver lineage biology. Hepatology 2011; 53:1035-45. 
14. He G, Dhar D, Nakagawa H, Font-Burgada J, Ogata H, Jiang Y, Shalapour S, Seki E, Yost SE, Jepsen K, Frazer KA, Harismendy O, Hatziapostolou M, Iliopoulos D, Suetsugu A, Hoffman RM, Tateishi R, Koike K, Karin M. Identification of liver cancer progenitors whose malignant progression depends on autocrine IL-6 signaling. Cell 2013; 155:384-96.

15. Yang ZF, Ngai P, Ho DW, Yu WC, Ng MN, Lau CK, Li ML, Tam KH, Lam CT, Poon RT, Fan ST. Identification of local and circulating cancer stem cells in human liver cancer. Hepatology 2008; 47:919-28.

16. Clayton E, Forbes SJ. The isolation and in vitro expansion of hepatic Sca-1 progenitor cells. Biochem Biophys Res Commun. 2009; 381:549-53.

17. Huang H., Hu M., Li P., Lu C., Li M. Mir-152 inhibits cell proliferation and colony formation of CD133+ liver cancer stem cells by targeting KIT. Tumour Biol. 2015; 36:921-8.
18. Tang KH, Ma S, Lee TK, Chan YP, Kwan PS, Tong CM, Ng IO, Man K, To KF, Lai PB, Lo CM, Guan XY, Chan KW. CD133 (+) liver tumor-initiating cells promote tumor angiogenesis, growth, and self-renewal through neurotensin/interleukin-8/ CXCL1 signaling. Hepatology 2012; 55:807-20.

19. Rountree CB, Ding W, Dang H, VanKirk C, Crooks GM. Isolation of CD133+ liver stem cells for clonal expansion. J Vis Exp 2011; 56:e3183.

20. Karakala M, Wicha MS. Implications of cancer stem cell hypothesis for breast cancer prevention and therapy. J Clin Oncol 2008; 28:2813-20.

21. Badr HA, AlSadek DMM, Darwish AA, Elsayed AI, Bekmanov BO, Khussainova EM, Zhang X, Cho WC, Djansugurova LB, Li CZ. Lectin approaches for glycoproteomics in FDA-approved cancer biomarkers. Expert Rev. Proteomics 2014; 11:227-36. 